\title{
O método Cooper, a mídia impressa e a emergência da corrida de rua como prática de saúde no Brasil: uma história de controvérsias e disputas
}

\author{
Glauber TIBURTINO ${ }^{1}$ \\ Alice GATTO ${ }^{2}$
}

\begin{abstract}
Resumo:
O presente artigo se propõe a debater o surgimento da corrida de rua no Brasil como uma prática de saúde que, posteriormente, passou a ser vista com ressalva e desconfiança. Pesquisadores e historiadores do esporte datam a década de 1970 como um marco da expansão da corrida de rua ao redor do mundo. No Brasil, a Copa do Mundo do México teve relevância nessa adesão, uma vez que a utilização do método Cooper pela seleção brasileira de futebol recebeu destaque midiático e a prática rapidamente ganhou aderência nas ruas. O próprio Dr. Kenneth Cooper orientava a corrida como uma das principais fontes de longevidade. Entretanto, essa atividade se mostrou controversa à medida que acidentes e mortes passaram a ocorrer no desempenho de sua prática. Nossa análise centra-se nessa controvérsia e toma por base os olhares e narrativas de meios de comunicação impressos do Rio de Janeiro nas décadas de 1970 e 1980 e da literatura científica em relação a essa disputa de sentidos da corrida de rua como atividade segura e saudável ou de risco.
\end{abstract}

Palavras-chave: corrida de rua; método Cooper; saúde; história; imprensa.

\section{The Cooper method, mass media and the growth of street run as health practice at Brazil: a history of controversies and disputes}

\begin{abstract}
:
This article aims to discuss the emergence of street running in Brazil as a health practice that after a while has come to be treated with suspicion. Sports researchers and historians date the 1970s as a milestone in the expansion of street racing around the world. In Brazil, the Mexico World Cup had relevance in this adhesion, because the use of the Cooper method by the Brazilian soccer team gained prominence in the press and the practice quickly gained adherence in the streets. Dr. Kenneth Cooper himself guided running as one of the main sources of longevity. However, this activity proved to be controversial as accidents and deaths started to occur due to their practice. Our analysis focuses on this controversy and is based on the looks and narratives of newspapers and magazines in Rio de Janeiro in the 1970 and 1980 decades and the scientific literature in relation to this dispute of meanings of street running as a safe and healthy or risky activity.
\end{abstract}

Keywords: street run; Cooper method; health; History; mass media.

\footnotetext{
${ }^{1}$ Mestre em Informação e Comunicação em Saúde (PPGICS/Fiocruz), especialista em Comunicação e Saúde e integrante do Núcleo de Estudos em Comunicação, História e Saúde (NECHS - Fiocruz/UFRJ). Assessor de Comunicação na Fundação Oswaldo Cruz.E-mail: glauber.tiburtino@gmail.com.

2 Doutoranda do Programa de Pós-Graduação em Informação, Comunicação e Saúde (PPGICS) da Fundação Oswaldo Cruz (Fiocruz), Mestre em Informação, Comunicação e Saúde (PPGICS/Fiocruz) e especialista em Comunicação e Saúde. Integra o Núcleo de Estudos em Comunicação, História e Saúde (NECHS - Fiocruz/UFRJ). E-mail: alice_gatto@yahoo.com.br.
} 


\title{
El método Cooper, los medios impresos y el surgimiento del carrera de calle como práctica de salud en Brasil: una historia de controvérsias y disputas
}

\begin{abstract}
Resumen:
Este artículo pretende discutir el surgimiento del carrera de calle en Brasil como una práctica de salud que después de un tiempo ha llegado a ser tratada con sospecha. Los investigadores e historiadores del deporte sitúan la década de 1970 como un hito en la expansión de las carreras callejeras en todo el mundo. En Brasil, el Mundial de México tuvo relevancia en esta adhesión, porque el uso del método Cooper por parte de la selección brasileña de fútbol ganó protagonismo en la prensa y la práctica ganó rápidamente adherencia en las calles. El propio Dr. Kenneth Cooper guió a correr como una de las principales fuentes de longevidad. Sin embargo, esta actividad resultó ser controvertida ya que comenzaron a ocurrir accidentes y muertes debido a su práctica. Nuestro análisis se centra en esta controversia y se basa en las visiones y narrativas de los medios impresos en Río de Janeiro en las décadas de 1970 y 1980 y la literatura científica en relación a esta disputa de significados de correr en la calle como una actividad segura y saludable o de riesgo.
\end{abstract}

Palabras clave: carrera de calle; método Cooper; salud; prensa; historia.

\section{Introdução}

A corrida de rua populariza-se no Brasil a partir da segunda metade do século XX, especialmente na década de 1970, por meio da adesão ao método Cooper como pretensa forma de prevenção de doenças crônicas e obtenção de saúde (DALLARI, 2009; ROJO, 2014; DIAS, 2017; TIBURTINO; SACRAMENTO, 2019). A metodologia de exercícios físicos aeróbicos analisada foi desenvolvida pelo cardiologista norte-americano Kenneth H. Cooper - militar das forças armadas, que aplicou seu método em astronautas - e prometia melhores desempenhos das funções cardíacas e pulmonares em seus praticantes (COOPER, 1970).

A controvérsia em relação a essa máxima, entretanto, teve início anos após seu surgimento, quando a imprensa carioca e a literatura científica começaram a registrar males súbitos, lesões e até óbitos decorrentes da prática - antes apresentada como saudável - e passaram a divergir acerca de sua adoção e incentivo. A partir disso, utilizamos a imprensa como fonte, objeto e agente histórico nesta análise, conforme definição de Fortes (2009). Observamos variações, tensões, contradições e disputas discursivas em relação ao papel da corrida de rua como fator de saúde ou de risco no período entre 1970 e 1985 . Essa contradição histórica, narrada e registrada pela mídia impressa da época, será desdobrada neste estudo.

Naqueles anos foi protagonista o programa de Kenneth Cooper calcado na promoção da prática de exercício físico para o desenvolvimento da resistência aeróbica, do qual o teste homônimo era um dos seus componentes com mais 
ampla disseminação. De lá para cá o conceito do "Cooper" ou de "fazer Cooper" passou a compor o imaginário social vinculado a uma vaga ideia de praticar alguma atividade física para manter um bom nível de saúde (PICH; GOMES; VAZ, 2007, p. 187).

Formulado a partir de estudos científicos cujos resultados geraram uma planilha de exercícios físicos aeróbicos que atrelava o aumento do "consumo de oxigênio" à elevação da "capacidade de resistência" de um indivíduo ativo (COOPER, 1970, p. 25), o método Cooper tinha na corrida a pé uma de suas principais prescrições. Em seu mais importante livro de divulgação do método, Aptidão física em qualquer idade (1970), o autor detalha o funcionamento do organismo daqueles que aderem à rotina de exercícios.

Os pulmões começam a trabalhar mais ar, com menos esforço, o coração fica mais forte, bombeando mais sangue, com menos batidas, o suprimento de sangue para seus músculos melhora, e o volume total de sangue aumenta. Em resumo, você melhora a capacidade do corpo para levar oxigênio e remetê-lo às células do tecido onde é associado ao alimento para produzir energia (COOPER, 1970, p. 25).

No Brasil, a popularidade da metodologia ganhou ainda mais notoriedade por ter sido aplicada na preparação da seleção brasileira de futebol campeã na Copa do Mundo do México, em 1970 (DALLARI, 2009; DIAS, 2017). Os exercícios foram introduzidos por intermédio do capitão Cláudio Coutinho, um dos preparadores físicos daquela equipe e ex-estagiário de Cooper. A dupla se conheceu em um congresso de medicina na França, em 1968, e da amizade surgiu a parceria profissional e acadêmica. Como dito, dos gramados mexicanos, os exercícios praticados pela seleção ganharam o solo carioca, especialmente sob a forma das corridas de rua, incentivados pelo sucesso do time e propagados em larga escala pela imprensa esportiva (DIAS, 2017; TIBURTINO; SACRAMENTO, 2019), conforme constatamos em publicações impressas no decorrer da pesquisa, como a do Jornal do Brasil de 26 de fevereiro de 1980:

Para o público brasileiro, a corrida pelas ruas vai sempre estar associada à figura do Dr. Kenneth Cooper, o Tenente-Coronel da Força Aérea norteamericana que um dia recebeu o convite para melhorar o preparo físico de seus companheiros de arma [...] e tornou-se até estreitamente ligado à campanha da Seleção Brasileira, campeã do mundo em 1970 (WERNECK, 1980, p. 33). 
Historicamente, como veremos, o período analisado foi marcado ainda por fatores sociopolíticos e culturais que impactaram a sociedade brasileira daquela época e de tempos vindouros, conformando muitos dos hábitos e convicções que passaram a ser praticados e disseminados a partir dali. Dentre essas mudanças, a consolidação de uma nova constatação na díade saúde-doença, na qual as doenças crônicas não transmissíveis, como a hipertensão arterial e o infarto do miocárdio, avolumavam-se estatisticamente, enquanto as doenças infectocontagiosas diminuíam suas incidências, consistindo na chamada "transição epidemiológica" (CZRESNIA; MACIEL; OVIEDO, 2013, p. 63). Além disso, destacaram-se também o movimento da Reforma Sanitária Brasileira, que amplia o conceito de saúde para além da ausência de doença (BUSS, 2000), a Ditadura Militar e, por consequência, o encorajamento de práticas esportivas ao ar livre voltadas para o autocuidado com a saúde, como o próprio método Cooper, que culminou na adoção da corrida de rua como hábito dos brasileiros (SALGADO; CHACON-MIKAHIL, 2006; DALLARI, 2009).

Para entendimento de como se deu essa produção discursiva da corrida de rua atrelada a configurações de saúde, adotamos a pesquisa documental como metodologia deste estudo acadêmico, utilizando - além de artigos e obras científicas - o material produzido pela imprensa no período analisado. Para a busca bibliográfica tradicional, consultamos arquivos físicos e digitais, via plataformas de pesquisas como Scielo, Biblioteca Virtual de Saúde e Google Acadêmico, utilizando descritores como "método Cooper" e "corrida de rua" nas buscas. Para pesquisa das publicações na imprensa, utilizamos os mesmos descritores e elencamos veículos impressos de grande circulação no Rio de Janeiro, cujo acervo estivesse digitalizado na Hemeroteca Digital da Biblioteca Nacional. A partir desses critérios, os meios de comunicação selecionados foram $O$ Globo, Jornal do Brasil, Jornal dos Sports e revista Manchete, na década de 1970.

As citações encontradas foram utilizadas ao longo do texto, caracterizando-se, assim, o uso da imprensa simultaneamente como fonte e objeto da pesquisa, uma vez que "os meios de comunicação vêm sendo cada vez mais utilizados pelos próprios historiadores, senão como a principal fonte de suas pesquisas, pelo menos como uma delas" (RIBEIRO, 2000, p. 40). O presente artigo está estruturado em três tópicos e dois grandes eixos. O primeiro eixo demonstra como a corrida de rua, por meio do método Cooper, se insere como prática sociocultural de 
obtenção de saúde como um hábito do carioca - e do brasileiro de modo geral -; e o segundo, que aponta e analisa as controvérsias envoltas na prática e as diferentes narrativas acerca dela.

O objetivo central do estudo consiste em historicizar o processo que marca o surgimento da corrida de rua no Brasil culturalmente como prática de saúde, sob o olhar da imprensa carioca, e evidenciar as controvérsias que marcam essa emergência. Nossos objetivos específicos, portanto, foram: analisar a origem histórica da corrida de rua como prática de saúde a partir do método Cooper, debater disputas, controvérsias e reconfigurações acerca do método na sociedade, pela narrativa da imprensa carioca, e compreender como - e em que contextos a corrida de rua emerge no cenário carioca e brasileiro na segunda metade do século XX.

Futebol, Cooper e a configuração cultural da corrida de rua como hábito de saúde pela imprensa carioca

A corrida de rua, entretanto, nem sempre buscou atender a apelos preventivistas de autocuidado e promoção da saúde ou a uma estética corporal socialmente pré-determinada. Seu início foi menos badalado do que inicialmente pode-se imaginar, como explica o historiador Victor Melo (2009):

O atletismo no século XIX tem uma trajetória curiosa. De início, não se tratava de uma prática relacionada à saúde ou higiene; era quase uma brincadeira organizada pelos ingleses que viviam no Rio de Janeiro. O programa era dos mais curiosos, notadamente nas provas de corridas, que previam categorias como o uso de sacos de estopa ou pernas de pau (MELO, 2009, p. 75).

Os primeiros registros da corrida de rua no Brasil datam ainda do século XIX: "as primeiras competições mais estruturadas foram organizadas em 1880, em um campo da rua Paissandu (Laranjeiras), por um grupo de ingleses ligados ao Rio Cricket Clube” (MELO, 2009, p. 75). Todavia, é a partir da década de 1970 que a atividade passa por uma reconfiguração sociocultural em decorrência de uma série de fatores. Entre eles, a transformação da prática, no período entre 1970 e 1985, "de um passatempo de alguns excêntricos em uma atividade central apreciada e entendida por milhões ao redor do mundo" (DALLARI, 2009, p. 27-28). A já debatida vinculação do método Cooper à seleção brasileira de futebol rendeu-lhe crédito e elogios por conta do desempenho físico dos atletas tricampeões mundiais na Copa do Mundo 
de 1970. Tal fato contribuiu com a promoção do método, que passou a ser disseminado pela imprensa esportiva, chegando posteriormente às ruas, parques e praias do país.

O futebol, portanto, chancelou e serviu de ferramenta introdutória do método Cooper no Brasil. Em setembro de 1970, dentro de um curto espaço de tempo, duas publicações de jornais impressos distintos corroboram esse entendimento. As reportagens intituladas "Tão em forma quanto a seleção" (1970, p. 6) e "O poder da preparação" (1970, p. 25), veiculadas no Jornal do Brasil e no Jornal dos Sports, respectivamente, denotam essa ênfase dada pela mídia. Ambos os textos jornalísticos tecem em suas produções midiáticas a adesão do método Cooper ao desempenho esportivo da seleção brasileira. Notamos ainda que foi a própria imprensa nacional quem se encarregou de transferir essa aplicação do campo esportivo para o cotidiano do brasileiro, elevando a prática da corrida a pé como um hábito de saúde. Tais registros nos servem para observar a influência do incentivo à prática dos exercícios aeróbicos na cultura do país.

Embora possamos afirmar que as "associações entre atividade física e saúde são tão antigas quanto à própria civilização" (FRAGA, 2006, p. 105), cientificamente tal concepção sobre fisiologia e esporte data apenas a partir da década de 1950, quando "foi possível verificar que o baixo nível de atividade física influenciava negativamente o desenvolvimento de doenças degenerativas" (FRAGA, 2006, p. 106). Ainda segundo o autor, com o término da Segunda Guerra Mundial, todo o aparato de preparação física dos soldados americanos foi revertido para o programa de formação dos atletas estadunidenses. A partir dali, a relação entre exercícios vigorosos e o aumento da capacidade cardiovascular passou a pautar diversas pesquisas e impulsionou laboratórios de estudos esportivos. Em pouco tempo as descobertas e novas recomendações do dueto saúde-esporte desceriam o continente americano:

No Brasil do início da década de setenta, "cooper" havia se tornado "marca registrada" das corridas de resistência aeróbica. Para Kenneth H. Cooper, o investimento em exercícios predominantemente aeróbicos era fundamental para a conservação da saúde, pois eles seriam responsáveis pela melhoria do sistema cardiorrespiratório que, por sua vez, repercutiria numa melhora geral do condicionamento físico e bem-estar geral de quem os praticasse com regularidade. Tais metas seriam resultantes "naturais" de um programa metodicamente estruturado em exercícios intensos e ininterruptos (50-60 minutos três vezes por semana), precedidos de avaliação médica; orientados por especialistas e mensurados pelo consumo de oxigênio (FRAGA, 2006, p. 106). 
Ainda sobre as reconfigurações culturais das atividades físicas, outra evidência, defendida por Dallari (2009), é que a corrida de rua passou por uma transformação na segunda metade do século XX, quando efetivamente se popularizou em escala global. Para Dias (2017), a partir dos anos 1970, a propaganda exagerada por parte da imprensa, sobretudo a esportiva, atrelou diretamente ao fenômeno "Cooper" o aumento dos praticantes de corrida de rua. Além disso, àquela altura, o método Cooper popularizava a ideia de que a saúde poderia ser obtida pela prática esportiva e mensurada por meio das formas corporais (TIBURTINO; SACRAMENTO, 2019, p. 274).

Em fevereiro de 1972, a revista Manchete publicou uma entrevista de quatro páginas com o autor do método, acompanhado de sua esposa. A matéria relembra a origem da prática a partir do futebol, mas amplia a abrangência dos exercícios para outras esferas sociais de forma entusiasmada, exaltando seus feitos e promessas. A chamada inicial tem o seguinte título: “Cooper. Seu método cura tudo: do enfarte ao tédio" (BIANCHI, 1972, p. 52). O subtítulo ratifica o ufanismo acerca do tema: "Mulheres grávidas, astronautas, doentes cardíacos, atletas campeões mundiais, diabéticos, crianças, jovens e adultos. Todos se beneficiam com os mais revolucionários exercícios de todos os tempos" (BIANCHI, 1972, p. 52). A referência à seleção brasileira de futebol reaparece logo na legenda da foto principal que ilustra a entrevista, onde se lê: "A força física do escrete do tri - sintetizada em Pelé e Gerson [...] - foi adquirida através dos exercícios aeróbicos. Isso tonou o professor Cooper, inventor do método, um homem famoso no Brasil” (BIANCHI, 1972, p. 52).

Outro influente agente na divulgação do método foi o comunicador e colunista esportivo de renome Armando Nogueira, que por diversas ocasiões preencheu sua coluna esportiva no Jornal do Brasil com elogios a Cooper. Segundo Nogueira (1972), além dos feitos futebolísticos, nas ruas o carioca se familiarizava cada vez mais com Cooper e seus ensinamentos. Em 20 de abril de 1972, o tema voltou a pautar sua coluna, com ênfase na sociabilidade da prática e sua configuração como hábito de saúde fisiológica. "Quem aparecer nas praias da Zona Sul, de manhã cedinho, vai sentir, como eu, que o professor Cooper está mesmo fazendo escola por aqui: é gente andando, marcha batida, gente correndo, gente pedalando, em busca de melhores pulmões e melhor coração" (NOGUEIRA, 1972, p. 39). 
O jornal do Brasil seguiu destacando o aspecto social do novo método em outras edições. Já no mês seguinte, o tema voltou à pauta como uma atividade cada vez mais estruturada no cotidiano do carioca. A prática ganhava incentivo e reconhecimento das autoridades:

Os praticantes do método de Cooper que frequentam a praia de Copacabana tiveram ontem uma surpresa: do posto dois ao seis o delegado Hermes Machado, diretor do Serviço de Salvamento, mandou colocar placas indicativas de cada 400 metros para facilitar os que praticam esse tipo de exercício (LANCE LIVRE, 1972, p.10).

Transformações na geografia e no espaço urbano carioca também foram e são influenciadas pelo advento da corrida de rua. As pistas de caminhada e corrida nas orlas e espaços públicos correspondem a uma expectativa de cidadãos comprometidos com sua "qualidade de vida" (PICH; GOMES; VAZ, 2007, p. 187-188). Os suportes estruturais na arquitetura para realização da corrida de rua tornam a aparecer no jornal em pouco mais de um mês após a notícia de instalação das placas em Copacabana:

[...] as placas indicativas dos percursos a pé ao longo da praia têm atraído aos exercícios moradores de bairros distantes, como João José, de 73 anos, que vem da Tijuca. Para encurtar a distância percorrida de ônibus, da qual o método não se ocupa, as praias de Botafogo e da Bica (Ilha do Governador) serão balizadas este mês e as de Ipanema e Leblon em agosto (ADEPTOS, 1972, p.5).

O acervo que nos serviu de fonte para este estudo indica a adoção, especialmente, da corrida de rua como forma de adesão do brasileiro ao método Cooper e prática de se obter saúde (DIAS, 2017, p. 3). Como já destacado, ainda que a metodologia possibilitasse a adoção de outras modalidades, como natação e ciclismo, a corrida logo caiu no gosto popular, sendo, inclusive, a atividade da preferência do próprio criador do método (COOPER, 1970, p. 27). Pesquisas recentes, cujos objetivos são estudar a motivação dos corredores de rua na contemporaneidade, apontam que o método Cooper também é relacionado com a adoção da corrida como hábito sociocultural nos anos 1970, no Brasil, e em várias partes do mundo:

O movimento denominado jogging boom, influenciado pela teoria do Método Cooper, estimulou o surgimento da cultura das corridas, em ambientes 
externos, nos Estados Unidos na década de 1960 e 1970. Essa prática rapidamente chega ao Brasil, talvez impulsionada pelo sucesso da seleção brasileira de futebol campeã na Copa do Mundo do México, no ano de 1970, que utilizou o teste de Cooper na preparação de seus jogadores (RODRIGUES; TRIANI; TELLES, 2018, p. 206).

Elencamos, portanto, a correlação entre a preparação física e o título da Copa do Mundo de 1970 como um importante fator de propulsão da corrida de rua no Brasil. Somente na coluna de Armando Nogueira, a menção direta ao uso do método Cooper foi feita nove vezes em 19 textos publicados no mês da competição de futebol, em junho de 1970. Embora os talentos individuais de uma geração brilhante tenham sido sempre reconhecidos, a vinculação do sucesso da preparação física daquela equipe com a conquista do tricampeonato mundial persistiu por muito tempo nas narrativas midiáticas, como observamos na cobertura jornalística da preparação para a Copa da Alemanha Ocidental, quatro anos após o tri. A revista Placar, em sua edição de março de 1974, foi enfática ao afirmar que "a seleção ganhou no México no preparo físico" (QUADROS, 1974, p. 4). Naturalmente, uma atividade prospectada com tantas promessas de benefícios rapidamente ganhou a confiança, o apreço e a aprovação popular. Entretanto, àquela altura a corrida de rua também já sofria questionamentos acerca da segurança de sua prática por parte da imprensa e da ciência.

A controvérsia do método Cooper e da corrida de rua como marca de uma emergência na imprensa

A adoção do método Cooper foi amplamente proposta como uma alternativa individual de autocuidado pela forma como foi expressa em diversas publicações na imprensa brasileira e na sociedade - a partir da década de 1970. A edição do Jornal do Brasil de 2 de dezembro de 1971, por exemplo, é emblemática para auxiliar na compreensão dessa concepção vigorante naquele período (TIBURTINO; SACRAMENTO, 2019). A capa do Caderno B foi composta por duas manchetes que expressavam as expectativas em relação ao método: "A luta da vida mais longa" e "A busca da forma melhor". A mesma página abrigou ainda outra nota, com o título: "Saúde aos 94 anos", contendo relato de um praticante do método como receita de saúde.

Logo, infere-se que a imprensa já referendava a realização regular de exercícios físicos como fator para obtenção de saúde e qualidade de vida, paralelamente ao crescimento do movimento sociopolítico da Reforma Sanitária Brasileira. A abordagem midiática já se pautava 
no sucesso do método desenvolvido por Cooper, como observado. Na já mencionada edição do Jornal do Brasil daquele 2 de dezembro, a página inteira de capa do Caderno B incentivava a atividade física como uma medida para o prolongamento da vida. "Diminuir a curva da barriga e aumentar a reta da vida: nas mais diversas faixas de idade, homens e mulheres começam a perceber a importância da aptidão física, não só por questões estéticas, mas também, e, principalmente, por motivos de saúde" (BOCCANERA, 1971, p. 1).

Outro exemplo dessa ocorrência se deu na também já citada edição de 24 de junho de 1972, quando mais uma vez o aspecto da corrida como elemento terapêutico foi destacado. A matéria intitulada "Adeptos do teste de Cooper sentem-se outros em 38 dias" continha as seguintes declarações:

Ninguém se queixa mais de fadiga nem dor muscular ou de cansaço ao subir escada; todos estão comendo e dormindo bem; muitos fizeram novas amizades nos breves intervalos de descanso, e não há um só que não se sinta fisicamente melhor 38 dias depois de iniciar, na praia de Copacabana, os exercícios pelo método Cooper [...] (ADEPTOS, 1972, p.5).

É importante ressaltar que embora houvesse um claro incentivo à prática de atividades físicas para melhoria da qualidade de vida, o próprio Kenneth Cooper também se preocupou em manifestar a enunciação do risco em relação à adesão à corrida ou caminhada sem a orientação, ou preparação adequada: "um dos mais sérios riscos, especialmente se esteve parado por muito tempo, é precipitar-se impetuosamente num programa de exercícios, convencido que pode acelerar o processo de condicionamento" (COOPER, 1970, p. 50). Os perigos que a prática desassistida poderia representar também foram abordados pela imprensa carioca, ainda que, inicialmente, de forma casual. $\mathrm{O}$ primeiro registro dessa natureza nos periódicos pesquisados ocorreu em $1^{\circ}$ de julho 1972, na seção de carta dos leitores do jornal $O$ Globo. A imprensa e a sociedade brasileira intensificariam, a partir de então, o debate sobre a controvérsia em relação à segurança do método até ali superestimado. O longo relato, com advertências e ponderações, foi feito por parte de um leitor que assinou o texto-denúncia como Lauro Lemos Luna:

Tenho lido na imprensa as mais elogiosas referências à "recente" prática do método Cooper em Copacabana, salientando-se num dos artigos os seus inegáveis benefícios à saúde corporal, tais como: desaparecimento de dores musculares, do cansaço, da fadiga [...] em primeiro lugar aquela prática não é recente e sim bem antiga, como podem atestar os que frequentam aquela praia 
geralmente das 6 às 7 horas da manhã. Há muitos anos, aficionados do exercício físico à beira-mar costumam fazer suas caminhadas ou corridas, conforme o caso, sendo de salientar, como exemplo, um grupo de quatro senhores que, há cerca de 18 anos, sob a liderança de um General-Médico com mais de 70 anos caminha diariamente do posto 6 ao 0 e volta na mesma marcha. [...] Há outro aspecto muito sério a ser salientado a propósito. Muitos correm e outros andam. Ambos os exercícios são de fato recomendáveis, inclusive pelo Cooper. Entretanto, é preciso saber quando é recomendado o exercício correndo e quando é recomendável o exercício andando [...] creio que ninguém deveria se aventurar a tais exercícios pelo simples entusiasmo (LUNA, 1972, p. 2).

O leitor encerra a carta relatando o caso trágico de um amigo que falecera praticando a corrida, supostamente incentivado pelo método Cooper. Em tom denunciativo, ele narra que o atestado de óbito do amigo apontara cardiopatia. Caso tivesse ciência de tal diagnóstico, conforme relata, a indicação de exercício físico mais adequada seria apenas a caminhada, em razão de sua condição de saúde. Na sequência, diversas matérias negativas sobre o método, outrora um aliado na prevenção de doenças crônicas e na promoção da saúde (CZRESNIA; FREITAS, 2009), passaram a ser veiculadas na imprensa. Uma nova matéria de $O$ Globo, publicada dias depois, questionava o método de forma mais estruturada, em uma entrevista com um especialista, o cardiologista Alberto Benchimol, diretor do Instituto de Diagnósticos e Pesquisas Cardiológicas do Good Samaritan Hospital: "Método de Cooper aos 40 anos pode causar enfarte, diz médico":

Impressionado com o que viu na Praia de Copacabana, onde pessoas maduras correm ofegantes, praticando o Método de Cooper, o cardiologista brasileiro Alberto Benchimol [...] disse que da maneira como está sendo exercitado não serve para nada, pois requer um esforço exagerado. Tornando-o sumariamente perigoso para pessoas de meia idade e pode provocar um enfarte [...] O dr. Alberto Benchimol, que vive há 10 anos nos Estados Unidos [...] se mostrava mais surpreso ainda com a popularidade do Método de Cooper no Brasil, que ele diz ser desconhecido nos Estados Unidos (MÉTODO, 1972, p. 10).

O Globo voltou a abordar a pauta entre os dias 20 e 22 de julho $^{3}$ e tornou a dar grande destaque para o método Cooper, ao destinar-lhe uma página inteira, na edição do dia 21 do

\footnotetext{
3 OS 'COOPERMANÍACOS' continuam correndo de manhã em Copacabana”. O Globo, Rio de Janeiro, p. 13, 20 jul. 1972; PARA MINEIRO quem corre cansa e assim Cooper está errado. O Globo, Rio de Janeiro, p. 12, 21 jul. 1972; ENTRE O ENFARTE e o bom senso. O Globo, Rio de Janeiro, p. 12, 21 jul. 1972; COOPER: risco não é o método, mas o exagero. O Globo, Rio de Janeiro, p. 12, 21 jul. 1972; MÉDICO acha perigoso o 'Cooper' sem orientação. O Globo, Rio de Janeiro, p. 3, 22 jul. 1972.
} 
mesmo mês. O consenso, contudo, passou longe das páginas e manchetes do jornal no período. A polêmica perdurou nas edições seguintes. Chamadas como: "Teste de Cooper é uma coisa, método é outra" (TESTE, 1972, p. 12) e "Cooper é bom, mas tem de ser feito com orientação" (COOPER, 1972, p. 12) foram outras abordagens realizadas em intervalos próximos, nos dias 25 de julho e 2 de agosto, respectivamente. Entre essas datas, no dia 27 de julho, a chamada principal da página 25 do jornal $O$ Globo estampava a frase: "Médicos apoiam a campanha do Governo contra o enfarte" (MÉDICOS, 1972, p. 25). À época, por ocasião do anúncio de uma campanha de prevenção ao infarto, promovida pelo governo federal, o jornal aproveitou-se da realização do VIII Congresso Internacional de Angiologia e ouviu alguns especialistas. Ao abordar o método Cooper na reportagem, o próprio desenvolvedor falou ao jornal.

[Cooper] acha recomendável e benéfica a prática de exercícios físicos para pessoas de qualquer idade como meio de evitar os males de uma vida sedentária, mas condena o uso sem critério do método de Cooper. Segundo afirmou, esteve em Copacabana e constatou que a prática do exercício vem sendo feita sem os cuidados de dosagem do esforço físico, notadamente para pessoas acima de 50 anos de idade (MÉDICOS, 1972, p. 25).

No mesmo dia dessa reportagem de $O$ Globo, o Jornal dos Sports também deu voz ao doutor Benchimol, em sua edição diária. A matéria intitulada "Uma opinião médica: calma com Cooper" contém um alerta do cardiologista brasileiro radicado nos Estados Unidos em relação aos cuidados prévios necessários para adoção da atividade física, como testes específícos e avançados capazes de detectarem eventuais problemas cardíacos. "Acontece que aqui no Brasil nenhum exame médico está sendo feito pelos adeptos do Método de Cooper. E daí a preocupação do Dr. Alberto Benchimol, que desaconselha exercícios muito puxados para pessoas que não tenham condições físicas necessárias" (UMA OPINIÃO, 1972, p. 8).

\section{Uma nova contranarrativa: Solomon e o embate literário ao método Cooper nos anos 80}

As contradições por parte da imprensa e literatura acerca da recomendação ou veto de atividades aeróbicas, como a corrida a pé, refletiam o grau de incerteza que pautava a própria sociedade em relação à (in)segurança da prática, a partir da ocorrência e divulgação de males súbitos e óbitos durante os exercícios físicos. Dessa forma, embora tenha incentivado muito a adesão à prática esportiva, a imprensa dos anos 70/80 - como formadora de opinião - não 
conseguia mais entrar em um consenso acerca dessa temática. Tal indecisão foi expressa, por exemplo, em um trecho da reportagem da revista Manchete, em junho de 1981: "Enquanto a alta classe média nutre a crença mística de que a capacidade de correr (cooper, jogging, etc.) ou realizar longas caminhadas protege as artérias coronárias, a grande maioria da classe média intermediária acredita que severos esforços físicos são prejudiciais" (CORONÁRIAS, 1981, p. 78). O texto traz demonstração de clara variação de entendimentos a partir de um recorte de classes econômicas, viés que pode ser aprofundado em outro estudo.

Com o passar do tempo, além da imprensa, a comunidade científica começou a questionar a fórmula desenvolvida por Cooper. Assim como Alberto Benchimol, no campo literário, o também cardiologista Henry Solomon foi um dos autores que buscaram desmitificar as benesses atribuídas aos exercícios aeróbicos e fez com que Cooper precisasse reforçar a defesa de seus argumentos. A obra $O$ mito do exercício (1984), que chegou ao Brasil em 1991, é uma das principais publicações que contrapõem os estudos de Cooper. "Mas apesar da noção bastante divulgada de que os exercícios físicos acrescentam mais alguns anos à sua vida, não há provas seguras disso. O envelhecimento biológico é uma realidade” (SOLOMON, 1991, p. 43). O autor taxava aqueles que acreditavam na ideia de que poderiam ter boa saúde correndo pelas ruas como "vítimas do mito do exercício". (SOLOMON, 1991, p. 9).

Esse embate científico-sanitário oitentista foi observado, descrito e analisado pelo pesquisador da Escola de Educação Física da Universidade Federal do Rio Grande do Sul, Alex Branco Fraga. O educador físico descreve alguns dos fatores que corroboraram o desgaste do método Cooper perante a opinião pública, sendo um dos principais, a morte de James Fixx um grande entusiasta dos exercícios aeróbicos, especialmente da corrida de rua - ocorrida durante a prática de sua rotina de exercícios:

Além destas e outras críticas oriundas do campo médico, um episódio ocorrido no mesmo ano em que Solomon publica seu livro, desestabilizou ainda mais a imagem positiva construída em torno da relação exercício físico e saúde. Em 20 de julho de 1984, James Fixx (popularmente conhecido como Jim Fixx), autor do livro "Guia completo de corridas", best seller que ficou entre 1977 e 1981 no topo da lista dos mais vendidos nos EUA, morreu fulminado por um ataque cardíaco durante uma de suas habituais corridas. A notícia "correu o mundo", as manchetes da época davam conta da dimensão do impacto no imaginário popular americano: Como pôde um homem jovem, que se exercitava regularmente e que pregava os benefícios de uma vida sã sair para 
uma corrida de fim de tarde, por uma estrada rural em Vermont, e cair morto? (FRAGA, 2006, p. 107).

Solomon buscava desvincular a noção de saúde à prática de exercícios vigorosos, visando especialmente reverter os efeitos dos estudos de Cooper na década anterior. E chegou a citar que a caminhada seria a forma mais saudável de exercitar-se, em um depoimento ao jornal O Globo, em 1986 (CIÊNCIA, 1986, p. 26). Em seu livro, ele reafirmava suas convicções: "Você pode apreciar os exercícios. Eles podem ser úteis socialmente, talvez façam você se sentir e parecer melhor. Mas o resto é mito. Os exercícios físicos não vão torna-lo mais saudável. Não vão prolongar sua vida. Preparo físico e saúde não são a mesma coisa" (SOLOMON, 1991, p. 17).

Diante de tais narrativas, Kenneth Cooper viu-se obrigado a contra-argumentar os ataques e lançou, em 1985, a obra Correndo sem medo. O próprio título já indicava que o objetivo da publicação seria recuperar a credibilidade abalada diante das fatalidades ocorridas e dos questionamentos em relação a seu método, ou seja, diminuir o estrago perante a opinião pública (FRAGA, 2006). "Eu estava convencido que alguém numa posição de saber teria que dissipar a preocupação reinante e responder a essas indagações - ou todo o movimento pelo exercício físico dos últimos quinze anos estaria em perigo" (COOPER, 1987, p.11).

Segundo Fraga (2006, p. 107-108), entretanto, a sentença dos exercícios aeróbicos naquele momento parecia dada: “Apesar dos esforços de Cooper para tentar dar novo ânimo à pregação aeróbica, 'Correndo sem medo' acabou se tornando uma espécie de 'epitáfio' desse movimento midiático que marcou o campo da atividade física na década de setenta do século XX”. Era a deixa para o crescimento das academias de musculação nos anos seguintes.

\section{Considerações finais}

Na conclusão do presente estudo, podemos refletir de forma mais crítica sobre a prática da corrida de rua e sua valoração sociocultural no Brasil como frutos de narrativas normatizadas que foram construídas e estruturadas em tempos recentes, porém, sob tensão. Atualmente, a corrida de rua é entendida como sinônimo de saúde, bem-estar, disposição e até mesmo de superação. Muitas dessas premissas, inclusive, são sustentadas por orientações médicas, que prescrevem a atividade física como qualidade de vida, sendo essa uma prática contemporânea. 
Entretanto, a história cultural da corrida de rua no Brasil revela que a adoção da prática se inicia sob um viés preventivista e avança na lógica neoliberal de uma saúde moralizada, sendo demarcada por disputas e controvérsias. De tão naturalizada e incentivada na década de 1970, a corrida de rua - a partir de Cooper - emergiu sob a égide da prevenção de doenças e, posteriormente, da promoção da saúde. Contudo, quando praticada de forma desassistida, começou a fazer vítimas. As controvérsias discursivas observadas neste estudo demonstram que a disseminação da prática dividiu a abordagem da imprensa - que atuou como um dos órgãos mediadores desse debate social -, concorrendo com depoimentos e relatos até então essencialmente positivos. As questões levantadas pela sociedade já não encontravam mais consenso nem na própria mídia e tampouco na literatura científica.

A contradição registrada na bibliografia documental analisada é uma das marcas da gênese da corrida de rua no Brasil. O apelo pela melhora de desempenho e condições individuais de saúde - como a prevenção ao infarto - foi um dos fatores cruciais para que o método Cooper ganhasse tantos adeptos no país a ponto de tornar-se um hábito sociocultural. Quando esse acordo tácito se rompe e a prática passa a ser vista com ressalvas e temor, a disputa discursiva eclode e diferentes narrativas surgem. Correr era saúde e virou risco, mas, àquela altura, o brasileiro já havia se acostumado com seu jogging nas orlas, parques, pistas e avenidas. Começava ali, com fundamental contribuição do método Cooper e mediação da imprensa, um novo capítulo da cultura do estilo de vida ativo em nossa sociedade. Com todos os dilemas e conflitos que cercavam essa prática pretensamente saudável.

\section{Referências}

ADEPTOS do teste de Cooper sentem-se outros em 38 dias. Jornal do Brasil, Rio de Janeiro, ano 82, n. 66, p. 5, 24 jun. 1972.

BIANCHI, Ney. Cooper cura tudo: do enfarte ao Tédio. Manchete. Rio de Janeiro, ano 20, n. 1.035, p.52-55, 19 fev. 1972.

BOCCANERA, Silio. A busca da forma melhor. Jornal do Brasil, Rio de Janeiro, ano 81, n. 204, 2 dez. 1971. Caderno B, p. 1. 
BUSS, Paulo Marchiori. Promoção da saúde e qualidade de vida. Ciência \& Saúde Coletiva, Rio de Janeiro, v. 5, n. 1, p. 163-177, 2000. Disponível em:

https://www.scielosp.org/article/csc/2000.v5n1/163-177/. Acesso em: 20 jun. 2020.

CIÊNCIA conclui que o exercício melhor é andar. O Globo, Rio de Janeiro, ano 61, n. 19.099, p. 26, 2 mar. 1986.

COOPER, Kenneth. Aptidão física em qualquer idade. Rio de Janeiro: Fórum, 1970.

COOPER, Kenneth. Correndo sem medo. Rio de Janeiro: Nórdica, 1987.

COOPER é bom, mas tem de ser feito com orientação. O Globo, Rio de Janeiro, ano 48, n. 14.193, p. 12, 2 ago. 1972.

CORONÁRIAS, elas comandam a vida e a morte. Manchete, Rio de Janeiro, ano 30, n. 1523, p. 77-79, 27 jun. 1981.

CZRESNIA, Dina; FREITAS, Carlos Machado de. Promoção da saúde: conceitos, reflexões, tendências. Rio de Janeiro: SciELO, Editora Fiocruz, 2009.

CZERESNIA, Dina; MACIEL, Elvira Maria Godinho de Seixas e OVIEDO, Rafael Antonio Malagon. Os sentidos da saúde e da doença. Rio de Janeiro: Editora Fiocruz, 2013.

DALLARI, Martha Maria. Corrida de rua: um fenômeno sociocultural contemporâneo. 2009. Tese (Doutorado em Educação) - Faculdade de Educação, Universidade de São Paulo, São Paulo, 2009. Disponível em: https://www.teses.usp.br/teses/disponiveis/48/48134/tde02092009-145957/en.php. Acesso em: 27 jul. 2020.

DIAS, Cleber. Corrida de rua no país do futebol. Recorde - Revista de História do Esporte, Rio de Janeiro, v. 10, n. 1, p. 1-32, jan./jun. 2017.

FORTES, Rafael. Os anos 80, a juventude e os esportes radicais. In: PRIORE, Mary Del; MELO, Victor Andrade de (org.). História do esporte no Brasil: do Império aos dias atuais. São Paulo: Editora Unesp, 2009. p. 417-451.

FRAGA, Alex Branco. Promoção da vida ativa: nova ordem físico-sanitária na educação dos corpos contemporâneos. In: BAGRICHEVSKY, Marcos; PALMA, Alexandre; ESTÊVÃO, Adriana; DA ROS, Marco (org.). A saúde em debate na Educação Física. Blumenau: Nova Letra, 2006. v. 2, p. 105-118.

LANCE LIVRE. Informe JB. Jornal do Brasil, Rio de Janeiro, ano 82, n. 28, p. 10, 11 maio 1972. 
LUNA, Lauro Lemos. Carta do Leitor. O Globo, Rio de Janeiro, ano 47 n. 14.161, p. 2, 1 jul. 1972. Disponível em: https://acervo.oglobo.globo.com/consulta-ao-acervo/. Acesso em: 10 jun. 2020.

MÉDICOS apoiam a campanha do Governo contra o enfarte. O Globo, Rio de Janeiro, ano 47, n. 14.187, p. 25, 27 jul. 1972.

MELO, Victor Andrade de. Corpos, bicicletas e automóveis: outros esportes na transição dos séculos XIX e XX. In: PRIORE, Mary Del; MELO, Victor Andrade de (org.). História do esporte no Brasil: do Império aos dias atuais. São Paulo: Editora Unesp, 2009. p. 71-106.

MÉTODO de Cooper aos 40 anos pode causar enfarte, diz médico. O Globo, Rio de Janeiro, ano 47, n. 14.179, p.10, 19 jul. 1972.

NOGUEIRA, Armando. Na grande área. Jornal do Brasil, Rio de Janeiro, ano 82, n. 10, p. 39, 20 abr. 1972.

PICH, Santiago; GOMES, Ivan Marcelo; VAZ, Alexandre Fernandez. Mercadorização biopolítica: sobre escolhas saudáveis em tempos de consumo. In: BAGRICHEVSKY, Marcos; ESTEVÃO, Adriana; PALMA, Alexandre (org.). A saúde em debate na educação física. Ilhéus: Editus, 2007. v. 3, p. 187-208.

O PODER da preparação. Jornal dos Sports, Rio de Janeiro, ano 40, n. 13.060, p. 25, 30 set. 1970.

QUADROS, Raul. A dureza vai aumentar. Placar, São Paulo, ano 4, n. 208, p. 4-9, 15 mar. 1974.

RIBEIRO, Ana Paula Goulart. A mídia e o lugar da história. Lugar Comum, Rio de Janeiro, n. 11, p. 25-44, maio/ago. 2000.

RODRIGUES, Jorge Pereira; TRIANI, Felipe da Silva; TELLES, Silvio de Cássio Costa. A teoria das necessidades e a busca da excitação: o que leva os corredores às ruas. Journal of Health Scienses, v. 20, n. 3, p. 205-11, 2018. Disponível em: https://doi.org/10.17921/24478938.2018v20n3p205-211. Acesso em: 10 jul. 2020.

ROJO, Jeferson Roberto. Corridas de rua, sua história e transformações. In: CONGRESSO SULBRASILEIRO DE CIÊNCIAS DO ESPORTE, 7., 2014, Matinhos, Paraná. Anais do VII Congresso Sulbrasileiro de Ciências do esporte. Secretarias do Colégio Brasileiro de Ciências do Esporte (Paraná, Santa Catarina, Rio Grande do Sul), 2014.

SALGADO, José Vítor Vieira; MIKAIL, Mara Patrícia Traina Chacon. Corrida de rua: análise do crescimento do número de provas e praticantes. Conexões, Campinas, SP, v. 4, n. 1, p. 90-98, 2006. Disponível em: 
https://periodicos.sbu.unicamp.br/ojs/index.php/conexoes/article/view/8637965. Acesso em: 12 ago. 2020.

SOLOMON, Henry. O mito do exercício. São Paulo: Summus, 1991.

TÃO em forma quanto a seleção. Jornal do Brasil, Rio de Janeiro, ano 80, n. 143, p. 6, 21 set. 1970.

TESTE de Cooper é uma coisa, método é outra. O Globo. Rio de Janeiro, ano 47, n. 14.185, p.12. 25 jul. 1972.

TIBURTINO, Glauber Queiroz Tabosa; SACRAMENTO, Igor. Correr para viver mais? O método Cooper e a construção discursiva da corrida como prática de saúde na imprensa carioca (1970-1979). Revista Latinoamericana de Ciencias de la Comunicación, v. 18, n. 32, p. 268-278, set./dez. 2019. Disponível em:

http://revista.pubalaic.org/index.php/alaic/article/download/1610/676. Acesso em: 23 jul. 2020 .

UMA OPINIÃO médica: calma com Cooper. Jornal dos Sports, Rio de Janeiro, ano 41, n. 13.726, p. 8, 27 jul. 1972.

WERNECK, José Inácio. Campo Neutro. Jornal do Brasil, Rio de Janeiro, ano 90, n. 320, p. 33, 26 fev. 1980.. Disponível em: http://bndigital.bn.gov.br/hemeroteca-digital/. Acesso em: 12 jun. 2020.

Submetido em: 30.09.2020.

Aprovado em: 07.11.2020. 